\title{
PENGARUH MODERNISASI TERHADAP PERILAKU SISWA SEKOLAH DASAR
}

\author{
Yunita Andriyani ${ }^{1}$, Muh. Husein Arifin ${ }^{2}$, Yona Wahyuningsih ${ }^{3}$ \\ 1,2,3PGSD Universitas Pendidikan Indonesia Kampus Cibiru \\ 1yunitaandriyani@upi.edu, ${ }^{2}$ muhusenarifin@upi.edu, ${ }^{3}$ yonawahyuningsih@upi.edu
}

\begin{abstract}
Modernization is an event that cannot be avoided by all countries in the world, especially Indonesia as a developing country. Modernization can occur in the world of education. Modernization is able to provide influence and impact on students if it is not monitored optimally by educators. The phenomenon of modernization can make elementary school students have an active, innovative and visionary mindset. But the phenomenon of modernization can also result in changes in the behavior of elementary school students, so it is feared that it will eliminate the noble character they have. This article discusses the impact and effects of modernization on the behavior of elementary school students. Furthermore, it will be discussed about the role of the teacher to minimize the negative impact of modernization which can endanger the character formation of elementary school students.
\end{abstract}

Keywords: noble character 1, modernization 2, behavior 3, basic education 4

\section{ABSTRAK}

Modernisasi merupakan peristiwa yang tidak dapat dihindari oleh semua negara di dunia, khususnya Indonesia sebagai negara berkembang. Modernisasi dapat terjadi dalam dunia pendidikan. Modernisasi mampu memberikan pengaruh dan dampak bagi siswa apabila tidak dilakukan pengawasan secara optimal oleh pendidik. Fenomena modernisasi dapat menjadikan siswa sekolah dasar memiliki pola pikir yang aktif, inovatif dan visioner. Tetapi fenomena modernisasi juga dapat mengakibatkan perubahan perilaku siswa sekoah dasar, sehingga dikhawatirkan akan menghilangkan karakter luhur yang mereka miliki. Artikel ini membahas tentang dampak dan pengaruh yang muncul dari adanya modernisasi bagi perilaku siswa sekolah dasar. Selanjutnya akan dibahas mengenai peran guru untuk meminimalisasi adanya dampak negatif dengan adanya modernisasi yang dapat membahayakan pembentukan karakter pada siswa sekolah dasar.

Kata Kunci: Karakter Luhur, Modernisasi, Perilaku, Pendidikan Dasar

\section{A. Pendahuluan}

Kehidupan masyarakat luas kini mengalami kemajuan yang sangat

pesat. Setiap individu maupun kelompok masyarakat tidak dapat membendung munculnya arus perubahan zaman seperti sekarang ini. Perubahan zaman yang cukup 
pesat ditandai dengan masuknya era milenial dan berubah menjadi zaman modern. Zaman modern ditandai dengan beranekaragamnya inovasiinovasi di bidang teknologi, komunikasi dan informasi. Inovasiinovasi yang terlahir tersebut dapat memberikan dampak semakin cepatnya laju perkembangan dan perubahan zaman.

Perkembangan dan perubahan ini terjadi pada banyak sektor kehidupan manusia. Sektor kebudayaan, sosial, ekonomi, kesehatan, teknologi dan informasi bahkan sektor pendidikan tidak luput dari perkembangan zaman. Modernisasi membawa kehidupan manusia menuju ke arah globalisasi. Informasi lintas dunia dapat diakses secara mudah dan cepat. Adanya modernisasi dan globalisasi dapat memangkas jurang pemisah dan jarak antarindividu dengan individu yang lain. Hal ini dapat menyebabkan perubahan secara masif pada keadaan sosial masyarakat di dunia (Nasution, 2018).

Perubahan hidup manusia dapat terjadi secara cepat atau lambat. Perubahan-perubahan tersebut dapat terjadi akibat adanya proses perubahan dalam pola kehidupan masyarakat (Soekanto, 2001). Manusia harus siap menerima perubahan yang datang dari sektor mana saja. Salah satu bentuk perkembangan modernisasi terjadi di bidang pendidikan, ilmu pengetahuan dan teknologi komunikasi serta informasi. Sebagai negara yang sedang mengalami perkembangan dalam berbagai bidang, Indonesia mengalami dampak perubahan secara kompleks dalam hal modernitas. Perubahan era modernisasi dalam dunia pendidikan akan berpengaruh dalam tercapainya tujuan pendidikan dan pengembangan ilmu pengetahuan secara luas. Modernisasi menjadi jembatan perubahan terhadap pola pikir siswa yang dapat dimanfaatkan sebagai sarana pembentukan karakter mulai dari jenjang pendidikan sekolah dasar dan seterusnya.

Modernisasi yang muncul di era milenial ini dapat menjadi tantangan para generasi muda untuk dapat lebih selektif dalam menerima setiap perubahan yang terjadi. Dibutuhkan peran pendidik yang berkompeten dan bertanggung jawab untuk membimbing siswa, khususnya pada jenjang sekolah dasar agar mereka dapat memahami adanya dampak- 
dampak yang timbul dari fenomena modernisasi dalam kehidupan mereka. Melalui artikel ini, penulis akan melakukan pembahasan seberapa besar pengaruh modernisasi terhadap siswa sekolah dasar pada umumnya. Pembahasan dimulai dengan mengetahui dampak dan pengaruh yang muncul dari adanya modernisasi bagi perilaku siswa sekolah dasar. Selanjutnya akan dibahas mengenai peran guru untuk meminimalisasi adanya dampak egative dengan adanya modernisasi yang dapat membahayakan pembentukan karakter pada siswa sekolah dasar.

\section{B. Metode Penelitian}

Dalam artikel ini, penulis menggunakan metode penelitian secara kualitatif. Selain menggunakan metode kualitatif, artikel ini memanfaatkan pendekatan fenomenologi untuk mendapatkan hasil pembahasan. Pendekatan fenomenologi merupakan ilmu yang memiliki orientasi penjelasan mengenai kejadian atau realitas yang dapat terlihat (Salim, 2006). Fenomenologi dapat dikatakan sebagai pengalaman yang muncul atau dirasakan oleh seseorang berdasarkan apa yang mereka lihat, mereka dapatkan serta mereka ketahui secara sadar (Hegel dalam Moutakas, 1994). Karena metodologi karya ilmiah ini cenderung menggunakan pendekatan fenomenologi, maka penulis tidak dapat melakukan proses pengembangan dan memasukkan asumsi pribadi dalam hasil pembahasan karya ilmiah tersebut (Creswell, 2014).

Artikel ini memuat tentang penjelasan yang bersifat deskriptif analisis tentang dampak dan pengaruh yang muncul dari adanya modernisasi bagi perilaku siswa sekolah dasar, dan peran guru untuk meminimalisasi adanya dampak negatif dengan adanya modernisasi yang dapat membahayakan pembentukan karakter pada siswa sekolah dasar. Penulis memanfaatkan studi kepustakaan (library research) untuk mendapatkan materi dan referensi untuk menghasilkan pembahasan yang relevan dengan permasalahan yang diangkat. Materi dan referensi studi kepustakaan yang penulis gunakan berasal dari bukubuku, literasi serta jurnal yang relevan dengan pembahasan artikel. 
C.Hasil Penelitian dan Pembahasan Teori dan Konsep Modernisasi

Modernisasi merupakan peristiwa yang tidak dapat dihindari oleh semua negara di dunia, khususnya Indonesia sebagai negara berkembang. Mengelak dan menjauh dari modernisasi sama halnya dengan menutup diri dari kemasyarakatan internasional. Situasi yang akan menyulitkan negara tersebut ketika mengadakan sistem pemerintahan dan menjalin kerja sama dengan negara lain. Modernisasi dinilai menjadi kajian yang sangat penting dalam mendukung perkembangan dan perubahan suatu.

Teori modernisasi sering kali bertentangan dengan istilah tradisional, modernisasi merupakan sebuah bentuk perubahan dari masyarakat tradisional menjadi wujud masyarakat yang modern dan mengikuti perkembangan zaman. Dalam proses modernisasi, masyarakat berusaha untuk keluar dari konvensi dan karakteristik kehidupan yang dapat menghalangi pengembangan diri (Martono, 2012). Masyarakat memiliki keinginan untuk maju dan tidak terbelenggu sistem adat dalam konsep tradisional.
Terjadinya

modernisasi didukung dengan adanya fenomena globalisasi. Di mana ilmu pengetahuan dan penguasaan teknologi, komunikasi serta informasi berkembang dengan pesat. Hal ini menyebabkan segala macam informasi dari luar negeri dapat diakses dari mana saja dengan mudah. Konsep hidup masyarakat berubah ke dalam pola dan sistem perekonomian yang praktis, politis yang bebas seperti halnya ciri-ciri negara barat yang tidak berubahubah. Hal itu menghasilkan aspekaspek kehidupan modern yang berwujud mekanisasi, pemanfaatan media masa, dan pengoptimalan teknologi (Battersby, Paul, Siracusa., 2009).

Perilaku yang mencerminkan modernisasi menganggap bahwa ilmu pengetahuan merupakan hal yang harus dipahami oleh semua masyarakat. Masyarakat modern mengedepankan akal sehat dan menyampingkan objek yang irasional. Hal ini yang menyebabkan modernisasi dapat dengan mudah diserap oleh generasi muda yang menjadi generasi penerus bangsa. Mereka mengedepankan sesuatu hal yang bersifat nyata, bukan sesuatu 
yang abstrak dan bersifat semu. Dengan hal tersebut, tidak dipungkiri bahwa teori modernisasi lebih mudah diterima oleh generasi muda di suatu negara.

Konsep modernisasi dibagi menjadi tiga bahasan, antara lain historis, relatif, dan juga analisis. Secara historis, konsep modernisasi disebut sebagai proses westernisasi. Konsep ini dipandang sebagai perilaku masyarakat yang lebih fokus pada kebudayaan barat daripada kebudayaan negara sendiri. Secara relatif, modernisasi dikatakan sebagai upaya masyarakat yang bertujuan agar dapat menyamakan standarisasi yang dianggap sebagai sesuatu hal yang modern, baik sebagai individu maupun dalam lingkungan kemasyarakatan. Sedangkan konsep modernisasi analisis lebih menitik beratkan fenomena modernisasi ke dalam bentuk dimensi masyarakat modern yang selanjutnya ditanamkan dalam kebudayaan masyarakat tradisional dan pra modern (Sztompka, 2004).

Modernisasi merupakan proses perubahan dari satu arah ke arah yang lainnya dalam konsep yang lebih maju atau mengalami peningkatan dari berbagai aspek kehidupan manusia. Konsep modernisasi memandang proses perubahan dari cara yang tradisional ke dalam caracara yang lebih maju dan rasional. Hal ini bertujuan untuk menjamin kesejahteraan masyarakat (Abdulsyani, 1994). Modernisasi menjadi fenomena di mana segala macam kemungkinan dapat dilakukan manusia secara mudah dengan memanfaatkan teknologi mutakhir dan penemuan terbaru yang mengedepankan konsep kesederhanaan dan kepraktisan (Moore, 1965).

Konsep modernisasi di negara Indonesia dan negara-negara lainnya dapat mempengaruhi bidang apapun. Salah satu bidang yang terpengaruh dengan adanya modernisasi adalah bidang pendidikan. Bidang pendidikan merupakan bidang yang paling sering bersinggungan dengan fenomena modernisasi. Hal ini dapat terjadi karena kajian dasar pada bidang pendidikan sangat berhubungan dengan ilmu pengetahuan dan teknologi yang sangat berkaitan erat dengan peristiwa modernisasi. Konsep modernisasi telah berkembang dalam dunia pendidikan dimulai dari pendidikan dasar, yaitu pada jenjang sekolah dasar, 
pendidikan menengah hingga pendidikan lanjutan atas.

\section{Pendidikan Dasar}

Pendidikan dasar merupakan salah satu komponen penyelenggaraan pendidikan yang paling mendasar di masa depan. Pendidikan dasar sangat diperlukan seorang manusia agar dapat bertahan hidup di lingkungan masyarakat dan dapat memilih apa yang mereka ingin kerjakan, serta dapat mengambil bagian sebagai dalam pembangunan masyarakat di masa depan secara bersama-sama serta dalam proses belajar pada tingkat lanjutan (Delors, 1996). Pendidikan dasar digunakan sebagai bekal agar manusia sebagai individu dapat ikut menyelenggarakan kehidupan dalam sistem masyarakat setempat, masyarakat dunia serta dalam lingkungan lembaga pendidikan selanjutnya. Seseorang layak mendapatkan pendidikan dasar yang layak dan memiliki mutu yang dapat dipertanggungjawabkan, sebab pendidikan dasar menjadi hak dan kesempatan yang harus diperoleh oleh setiap manusia.

Di Indonesia, pendidikan dasar dimulai dari jenjang sekolah dasar. Pendidikan dasar di Indonesia masuk ke dalam klasifikasi penyelenggaraan pendidikan nasional. Semua anak dengan usia 7 tahun wajib untuk mendapatkan pendidikan tingkat dasar yang layak dan bermutu (BSNP, 2006). Hal ini disebabkan pada usia tersebut, seorang anak tengah memasuki usia yang siap untuk mendapatkan pendidikan untuk membangun karakter yang berkualitas di masa depan.

Pendidikan dipandang sebagai sebagai cara untuk dapat menghadapi segala macam bentuk harapan, citacita serta tantangan yang nantinya muncul di masa depan. Pendidikan dasar kemudian dinobatkan sebagai bagian dari esensi kehidupan manusia, yang berfungsi untuk melewati perkembangan individu maupun perkembangan masyarakat. Dunia pendidikan memiliki visi dan misi agar semua masyarakat tanpa terkecuali dapat melakukan pengembangan bakat secara individu secara penuh serta dapat mewujudkan segala bentuk potensi kreativitasannya. Selain itu, pendidikan dasar juga dapat memupuk rasa tanggung jawab dalam kehidupan sendiri maupun kehidupan bermasyarakat serta tercapainya tujuan yang telah direncanakan. Semua visi dan misi tersebut akan 
terwujud

$$
\text { apabila }
$$

manusia

menerapkan

prinsip

learning

throughout life dalam hidupnya.

Pendidikan dasar dapat

melahirkan semangat bagi individu yang menjalankan. Hal ini akan memberikan manfaat dan kesadaran dalam menjalani tantangan kehidupan di masa depan. Selain itu, pendidikan dasar akan menjadikan seorang individu siap dalam mengelola proyek dan tantangan kehidupan bermasyarakat di masa sekarang dan masa yang akan datang. Pendidikan dasar dapat diproyeksikan sebagai pengetahuan untuk membangun karakter siswa melalui bentuk sosialisasi dan interaksi antarsiswa dalam satu instansi pendidikan. Untuk mewujudkan hal tersebut, dibutuhkan peran pendidik serta komponen pendidikan lainnya agar dapat mewujudkan hakikat pendidikan dasar yang fleksibel dalam perubahan zaman seperti sekarang ini.

Untuk menjelaskan materi pengaruh modernisasi terhadap perilaku siswa sekolah dasar digunakan beberapa literasi dan penelitian terdahulu yang sesuai dengan pembahasan, antara lain. Pertama, artikel yang berjudul Modernisasi Pendidikan di Indonesia
Sebuah Perspektif Sosiologis terhadap Dunia Pendidikan di Indonesia, artikel ini ditulis oleh Ankarlina Pandu. P dan Dwi Kasi. K pada tahun 2014. Artikel tersebut dimuat di Jurnal Analisa Sosiologi. Artikel tersebut menjelaskan tentang modernisasi menimbulkan kesenjangan yang sangat terlihat dalam dunia pendidikan. Hal ini kemudian menempatkan dan menyatakan bahwa modernisasi menimbulkan dampak yang kurang baik dalam perspektif sosiologi, khususnya dalam segala hal yang berkaitan dengan kesenjangan antara si kaya dan si tidak mampu. Kedua, artikel dengan judul Pola Asuh Orang Tua dalam Penggunaan Media Sosial Facebook pada Anak Sekolah Dasar, artikel diterbitkan dalam Jurnal Sosial Horizon pada tahun 2019. Artikel ini ditulis oleh Tri Gunawan, dan Sajidah Muhabbatilah. Artikel tersebut membahas tentang dampak adanya globalisasi dan modernisasi, khususnya dalam bidang teknologi yang dialami oleh siswa sekolah dasar. Dibutuhkan peran orang tua secara langsung dalam menanggulangi dampak dan kebiasaan siswa ketika memainkan media sosial di gadget mereka. 
Ketiga, artikel yang berjudul Pendidikan dan Modernisasi, ditulis oleh Anggelika Permata. S, Cahaya Melynia, Harun Ar Rasyid Lim Seong Been pada tahun 2021. Artikel tersebut menjelaskan tentang hakikat pendidikan sebagai salah satu bentuk ikhtiar manusia dari dalam diri sedangkan modernisasi merupakan cara ikhtiar ke luar diri dari pribadi manusia itu sendiri. Untuk mewujudkan sebuah modernisasi dalam dunia pendidikan, dibutuhkan peran pendidikan agar mencapai terbentuknya karakter yang baik bagi siswa serta bertujuan sebagai bentuk pengembangan teknologi yang menunjang segala bentuk hadirnya modernisasi dalam dunia pendidikan.

Dampak dan Pengaruh Modernisasi terhadap Perilaku Siswa Sekolah

\section{Dasar}

Modernisasi membawa dampak bagi pendidikan dasar di Indonesia. Modernisasi dapat menciptakan kemajuan dalam dunia pendidikan tetapi juga dapat mendatangkan kemunduran bagi siswa di jenjang sekolah dasar. Dampak positif dari modernisasi antara lain, adanya kemudahan dan kebebasan akses informasi dan pengetahuan dari seluruh dunia. Modernisasi menuntut siswa sekolah dasar untuk aktif dan dapat berpikir kritis dalam menanggapi semua fenomena yang mereka temui. Pendidik akan mengalami peningkatan kualitas, sebab pemerolehan materi pembelajaran dirasa tidak ada batasan. Hal ini dilakukan dengan cara memaksimalkan teknologi mutakhir yang ada di era modern. Kualitas pendidikan di Indonesia, khususnya pada tingkat dasar akan mengalami kemajuan dan pembaharuan metode pembelajaran yang sangat inovatif. Selain itu, modernisasi memiliki peran dalam proses pembelajaran siswa sekolah dasar agar dapat menghasilkan karya yang inovatif melalui pengetahuan ilmu pengetahuan dan teknologi secara modern.

Tidak hanya menghasilkan dampak positif yang mendukung perkembangan dan kemajuan siswa sekolah dasar, modernisasi juga dapat menimbulkan dampak yang negatif antara lain, dengan adanya kebebasan dan kemudahan akses informasi maka kehidupan siswa sekolah dasar rawan mengalami dekadensi moral. Diperlukan sensor dan kontrol dari guru serta orang tua untuk meminimalisasi hal tersebut. 
Modernisasi membawa pengaruh terhadap kesenjangan sosial siswa dalam mendapatkan pendidikan yang layak dan bermutu. Modernisasi dapat mengancam kestabilan budaya lokal karena siswa sekolah dasar lebih memilih budaya barat sebagai tren yang mereka ikuti, meskipun belum mereka ketahui budaya tersebut cocok atau tidak diterapkan di negaranya. Hal itu akan menimbulkan tradisi serba instan pada siswa sekolah dasar, sehingga mereka tidak menghargai proses dalam perkembangan belajar mereka.

Dampak-dampak yang muncul dari fenomena globalisasi kemudian menimbulkan pengaruh terhadap perilaku siswa sekolah dasar. Dunia pendidikan yang selalu mengalami perubahan dan pergerakan dalam proses aktualisasinya sering kali menyebabkan siswa sekolah dasar merasa belum siap dalam menerima segala pengaruh yang muncul. Hal ini berkenaan dengan adanya modernisasi yang sudah menjadi tuntutan semua masyarakat, tanpa terkecuali bagi siswa sekolah dasar. Melalui modernisasi, mereka memiliki pola pikir yang visioner dan revolusioner menuju ke arah depan. Mereka mudah menguasai teknologi mutakhir, pemanfaatan media sosial, dsb. Mereka secara mudah dapat mengakses informasi apa saja melalui gawai yang mereka miliki.

Siswa sekolah dasar belum memiliki daya nalar dan penguasaan emosi dengan seimbang. Percepatan proses modernisasi tersebut sering kali mempengaruhi perilaku seharihari mereka. Pengaruh yang paling terlihat yaitu ketidakcakapan siswa sekolah dasar dalam rangka memanfaatkan media sosial dengan bijak. Pengaruh modernisasi dapat menyebabkan siswa sekolah dasar mengalami dekadensi moral dan kehilangan karakter. Perilaku serba modern menyebabkan siswa sulit untuk menghargai proses dalam memperoleh sesuatu. Mereka terpengaruh budaya instan untuk memperoleh tujuannya, sehingga kerap kali mereka menghalalkan segala cara untuk meraih tujuan yang ingin mereka capai.

\section{Peran Guru untuk Meminimalisasi}

Pengaruh Negatif Modernisasi

Guru sebagai fasilisator dalam dunia pendidikan harus mampu meminimalisasi

pengaruh modernisasi terhadap perilaku siswa sekolah dasar. Guru harus menyiapkan siswa agar memiliki 
karakter yang unggul dan siap menerima modernisasi tanpa mengubah budaya dan nilai-nilai luhur yang telah tertanam dalam diri siswa (Hafid, dkk., 2013). Dalam proses pembelajaran, guru harus mengedepankan tujuan pendidikan karakter pada siswa.

Usia siswa sekolah dasar merupakan usia yang memiliki peran penting dalam pertumbuhan kecerdasan. Guru dan orang tua diharapkan mampu menanamkan nilai karakter luhur untuk meminimalisasi dampak negatif modernisasi. Guru memiliki karakter yang tangguh, sehingga dapat melakukan kontrol terhadap perilaku siswa sekolah dasar. Seorang guru memiliki tanggung jawab untuk mencetak kualitas SDM yang unggul dan mampu bertahan di tengah cepatnya perubahan zaman (Bahar, 2016). Modernisasi membawa guru agar dapat lebih kreatif dan inovatif dalam menyampaikan materi pembelajaran berbasis pendidikan karakter. Hal itu dilakukan agar siswa sekolah dasar tidak mengalami pembunuhan karakter dan perubahan perilaku yang diakibatkan oleh masuknya modernisasi dalam kehidupan mereka.

\section{E. Kesimpulan}

Berdasarkan pembahasan yang telah penulis jelaskan mengenai pengaruh modernisasi terhadap perilaku siswa sekolah dasar dapat ditarik simpulan bahwa modernisasi menjadikan siswa dapat berpikir secara visioner dan inovatif. Tetapi modernisasi juga dapat menyebabkan siswa kehilangan karakter luhur budaya timur sebab dengan mudahnya akses informasi dari budaya lain yang tidak sesuai dengan nilai-nilai luhur yang dianut. Siswa sekolah dasar dikhawatirkan mengalami dekadensi moral, sehingga dibutuhkan peran guru untuk mengembalikan perilaku baik siswa ketika menjalani proses modernisasi. Guru sebagai kontrol sosial untuk menghasilkan SDM yang berkualitas melalui dunia pendidikan. Saran kepada guru agar dapat menemukan metode pembelajaran yang tepat dalam rangka meminimalisasi adanya pengaruh modernisasi bagi perilaku siswa sekolah dasar. Selalu menyelipkan nilai-nilai luhur dalam pembelajaran agar siswa tidak kehilangan karakter dan jati diri dalam proses modernisasi yang sedang terjadi. 


\section{DAFTAR PUSTAKA.}

Abdulsyani. (1994). Sosiologi, Skematika, Teori, dan Terapan. Jakarta: Bumi Aksara.

Bahar, H. (2016). Etika dan Profesi Kependidikan. Edited by Siska Kusumawardani. Jakarta: FIP Universitas Muhammadiyah Jakarta, nd.

Battersby, Paul, dan Joseph M. Siracusa. (2009). Globalization and Human Security. United States of America: Royman and Little Field Publisher.

Brabender, V., \& Fallon, A. (2009). Group development in practice: Guidance for clinicians and researchers on stages and dynamics of change. American Psychological Association.

Creswell, J. W. (2014). Research Design: Pendidikan Kualitatif, Kuantitatif, dan Mixed. Yogyakarta: Pustaka Belajar.

Delors, J. (1996). Learning: The treasure within (Report to UNESCO on the International Commis sion on Education for the Twenty-First Century, Paris UNESCO 1996). Internationales Jahrbuch der Erwachsenenbildung, 24(1), 253258.

Gunawan, T., \& Muhabbatillah, S. (2019). Pola Asuh Orang Tua dalam Penggunaan Media Sosial Facebook pada Anak Sekolah Dasar. Sosial Horizon: Jurnal Pendidikan Sosial, 6(1), 82-95.

Hafid, Anwar, dkk. (2013). Konsep Dasar IImu Pendidikan. Bandung: Alfabeta.
Martono, N. (2012). Sosiologi perubahan sosial: Perspektif klasik, modern, posmodern, dan poskolonial (sampel halaman). RajaGrafindo Persada Jakarta.

Moore, W. E. (1965). Social Verandering dalam Social Change. Diterjemahkan oleh A. Basoski, Prisma Boeken, Utrech, Antwepen. Moustakas, C. (1994). Phenomenological research methods. Sage publications.

Ms, A. S. (2006). Teori dan Penelitian Paradigma.

NASIONAL, P. O. S. U., TSANAWIYAH, M., \& ALIYAH, M. (2006). Badan Standar Nasional Pendidikan.

Nasution, R. D. (2018). Pengaruh modernisasi dan globalisasi terhadap perubahan sosial budaya di Indonesia. Jurnal Kominfo, 1-14.

Primadata, A. P., \& Kusumawati, D. K. (2018). Modernisasi pendidikan di Indonesia sebuah perspektif sosiologis terhadap dunia pendidikan di Indonesia. Jurnal Analisa Sosiologi, 3(1).

Melynia, C., Rasyid, H. A., \& Sari, A. P. (2021). Pendidikan dan Modernisasi.

Soekanto, Soerjono. (2001). Sosiologi Suatu Pengantar. Jakarta: Raja Grafindo Persada.

Sztompka, P. (2004). Sosiologi Perubahan Sosial, Jakarta: Prenada Media. Diambil pada Tanggal, 17. 